\title{
Wyoming Physicians Are Significant Providers of Safety Net Care
}

\author{
Sharon A. Dobie, MCP, MD, Amy Hagopian, PhD, Beth A. Kirlin, BA, and \\ L. Gary Hart, PhD
}

Background: This study describes the contributions of family and general practice physicians from Wyoming to the health care safety net.

Methods: We surveyed family and general practice physicians in Wyoming about provider demographics, practice composition, and policies for treating the underinsured or uninsured. Two-tailed $\chi^{2}$ tests and limited logistic regressions were used to test for differences among characteristics of safety net providers.

Results: From a $50 \%$ response rate, $61 \%$ made less than the national mean family physician income $(\$ 130,000)$, and women are less likely than men to make this mean income, even when controlling for hours worked (OR, 0.09; CI, 0.009, 0.862). Close to two thirds claimed bad debt of over $\$ 10,000$, and $\mathbf{2 9 . 3 \%}$ noted forgiven debt of over $\$ \mathbf{1 0 , 0 0 0}$. Physicians with less income than the prior year were more likely to decrease their charity care.

Conclusions: Wyoming family and general practice physicians provide significant amounts of informal safety net care, which is threatened by income loss. Thoughtful public policy is needed to ensure that vulnerable rural Americans have access to care that is not tied to the financial well being of their health care providers. (J Am Board Fam Pract 2005;18:470-7.)

In 2003, the U.S. Census Bureau reported that 43.6 million Americans were uninsured, with a disproportionate number of these uninsured residing in rural areas. ${ }^{1}$ These Americans, their underinsured counterparts, and even their Medicaid- or Medicare-insured counterparts increasingly relied on a loose and informal network of public and private health centers and hospital emergency and urgent care departments for all or parts of their care. For these services, the term "safety net" has been applied, which can include charity care and bad debt. Charity care is free, discounted, or forgiven charges for care delivered to those deemed unable to pay all or a portion of their billed care and can apply to the uninsured along with the publicly and privately insured. Bad debt comprises losses from services for

Submitted 24 March 2005; revised 28 July 2005; accepted 29 July 2005.

From the Rural Health Research Center, University of Washington.

Funding: This University of Washington Rural Health Research Center study was funded by the federal Office of Rural Health Policy, Health Resources and Services Administration, Department of Health and Human Services.

Conflict of interest: none declared.

Corresponding author: Sharon Dobie, MCP, MD, University of Washington, Department of Family Medicine, Box 356390 , Seattle, WA 98195-6390 (e-mail: dob@u.washington.edu). which a bill was submitted and the patient was expected to pay. ${ }^{2}$

Several studies have noted that the safety net is tenuous, with physicians accepting financial burden when caring for the underserved. ${ }^{3-5}$ Rural private physicians are not only a main source of care for these Americans, they also provide stability in communities with fewer resources. ${ }^{4}$

This capacity to provide charity care is dynamic. Studies suggest that 28 to $33 \%$ of American physicians do not provide charity care. ${ }^{6}$ The Center for Studying Health Systems Change demonstrated the proportion of physicians providing charity care dropped from $76 \%$ to $72 \%$ between 1997 and 1999. In 2003, it reported the safety net had deteriorated in $25 \%$ of the surveyed communities. ${ }^{7}$ At the same time, between 2001 and 2003, 1.6 million Americans were removed from publicly financed health care programs, with 34 states cutting their Medicaid budgets. ${ }^{8}$

A 2002 study in New Mexico found the reduced availability of Medicaid funding to be largely accommodated through provider increases in workload and financial stress. ${ }^{9}$ Among the 246 rural counties in a study specific to the rural safety net, $17 \%$ were at risk for losing access to charity care services because of the negative operating margins of their hospitals. ${ }^{10}$ 
Our study followed site visits to 7 rural communities, where between 20 and $40 \%$ of the residents were uninsured or underinsured. Interviewed physicians indicated that private primary care practices were important providers of free or subsidized care. ${ }^{11}$ The current study describes the safety net participation of primary care physicians in one largely rural western state, Wyoming, where $16.4 \%$ of the residents are uninsured, compared with $14.7 \%$ nationally. U.S. Census Bureau information for those without health insurance for the year; national average is from 2001. The Wyoming average represents 3 years, 2000-2002 〈http://www. census.gov/hhes/hlthins/hlthin02/hi02t4.pdf).

\section{Methods}

\section{Study Design}

A 2-page questionnaire was sent to all 161 family practitioners (FPs) and general practitioners (GPs) identified by the Wyoming Medical Association as practicing in the state.

\section{Survey Development and Administration}

Survey questions were developed following the series of rural site visits that led to this study. ${ }^{11}$ The survey collected provider demographic and practice information, including age, gender, years in practice, specialty, hours worked per week, hours spent in direct patient care, type of practice and ownership, and practice policies regarding caring for Medicaid patients and patients needing other payment options. We asked respondents to estimate the proportion of all patient visits covered by different payment possibilities (ie, private not discounted, private discounted, Medicare or Medicaid, free care, sliding scale, negotiated installment plan, bad debt, and debt forgiveness) and to note changes in policies during the prior 2 years. We defined free care as care that was given away with no attempt to bill. We defined bad debt as care that was billed but not collected, and debt forgiveness as care that was billed, negotiated, and nonpayment of the whole or portion forgiven. We asked respondents whether their net salary was more or less than the mean income for family physicians in that year $(\$ 130,000)$. Last, we asked them to comment on their contribution to charity care relative to others in the community and relative to their practices 2 years earlier.
The questionnaire was tested with 7 (4 rural) family practice physicians in Washington state and revised with a 15 - to 20-minute completion time. An introductory letter was co-signed by a family physician representing the state's medical association. Surveyed physicians received up to 3 mailings.

\section{Data Analysis}

Data were double entered to ensure accuracy using EpiInfo 6.0, and were analyzed in SPSS 10 for the Macintosh. Respondent physician zip codes were used to classify their rural-urban commuting area (RUCA) codes. $^{12}$ This geographic taxonomy is based on U.S. Census Bureau-designated urbanized areas and places and work commuting patterns, and it categorizes areas as urban, large rural, small rural, and isolated smaller rural.

Our main interest was to describe the characteristics associated with larger (versus smaller) contributions to care for the underinsured and uninsured. When comparing groups, we used 2-tailed $\chi^{2}$ tests to test for the significance of differences (eg, gender and percentage of visits that were publicly funded). Because of the small sample size and the variable number of missing values for different questions in the study, we collapsed some responses into dichotomous categories based on closest quartiles or medians. We performed limited logistic regression analysis to control for possible associations with income level and to explore possible predictors of a decreased amount of charity care over the prior 2 years.

Nonrespondents were compared with respondents, and there was no statistically significant difference based on rural or urban location, or by gender.

\section{Results}

\section{Physician Characteristics}

The response rate was $50 \%$. The mean age of responding physicians was 45.8 years, and $83.1 \%$ were male. They had been in practice for a mean of 15 years (range 2 to 40 years), with a mean of 11.5 years in their current practice location. Approximately $39.0 \%$ of respondents had been in their Wyoming community $\leq 7$ years, with only $5.2 \%$ having practiced in their communities $\geq 25$ years. Of respondents, $88.2 \%$ were FPs and $11.8 \%$ were GPs. 
The majority of respondents ( 47 or $60.3 \%$ ) reported making less than $\$ 130,000$, the national mean for FPs in the study year (Table 1). Women physicians earned significantly less than their male counterparts. When we controlled for gender, hours of direct patient care, years in practice, and urban-rural practice, only female gender remained significantly associated with income less than $\$ 130,000$ (OR $=0.09, \mathrm{CI}=0.009,0.862)$.

Between the 2 income groups, there was little variability in employer or practice type. Overall, however, only $11.7 \%$ of respondents were employed by a hospital, whereas $40.3 \%$ were in solo, self-employed practices. The number of years in practice was not associated with income differences.

Fewer than $25 \%$ of physicians answered that they spent under 35 hours a week on direct patient care, whereas $50 \%$ said they devoted at least 45 hours per week to direct patient care (not tabled). Reported office-based ambulatory patient visits per week ranged from 12 to 200 per physician, with a mean of 88 . Other patient care visits included means of 11.7 inpatient visits, 6.3 emergency department visits, and 5.2 nursing home visits per week.

\section{Characteristics of the Safety Net}

The typical physician had a combined $43.2 \%$ of visits that were with public insurance patients and/or lost to debt forgiveness, free care, or bad debt. Only $15 \%$ reported having no discounted visits.

\section{Public Insurance: The Formal Safety Net}

Approximately $47 \%$ of physicians reported more than $30 \%$ of their patient visits were with patients who had Medicare, Medicaid, or other public insurance discounts (Table 2). Only one respondent did not care for Medicaid patients, and $84.4 \%$ had limits in caring for Medicaid patients. Limitations included limiting the number (13.6\%), limiting the age $(6.8 \%)$, limiting care to those already in the

Table 1. Characteristics of Wyoming Physician Respondents by Income

\begin{tabular}{|c|c|c|c|}
\hline & $\begin{array}{l}\text { Annual Income } \\
\geq \$ 130,000(\%)\end{array}$ & $\begin{array}{l}\text { Annual Income } \\
<\$ 130,000(\%)\end{array}$ & $\begin{array}{l}\text { Total Number of } \\
\text { Respondents (N) }\end{array}$ \\
\hline Number & 31 & 47 & 78 \\
\hline $\begin{array}{l}\text { Gender* } \\
\text { Male } \\
\text { Female }\end{array}$ & $\begin{array}{r}46.8 \\
7.7\end{array}$ & $\begin{array}{l}53.2 \\
92.3\end{array}$ & $\begin{array}{l}62 \\
13\end{array}$ \\
\hline $\begin{array}{l}\text { Years in practice } \\
0 \text { to } 7 \\
8 \text { to } 15 \\
16 \text { to } 25 \\
>25\end{array}$ & $\begin{array}{l}38.1 \\
42.9 \\
33.3 \\
55.6\end{array}$ & $\begin{array}{l}61.9 \\
57.1 \\
66.7 \\
44.4\end{array}$ & $\begin{array}{r}21 \\
21 \\
24 \\
9\end{array}$ \\
\hline $\begin{array}{l}\text { Location of practice } \\
\text { Urban } \\
\text { Rural }\end{array}$ & $\begin{array}{l}16.7 \\
46.4\end{array}$ & $\begin{array}{l}83.3 \\
53.6\end{array}$ & $\begin{array}{l}18 \\
56\end{array}$ \\
\hline $\begin{array}{l}\text { Employer } \\
\text { Solo, Self-Employed } \\
\text { Private Clinic } \\
\text { Hospital } \\
\text { Other }\end{array}$ & $\begin{array}{l}45.2 \\
26.9 \\
66.7 \\
33.3\end{array}$ & $\begin{array}{l}54.8 \\
73.1 \\
33.3 \\
66.7\end{array}$ & $\begin{array}{r}31 \\
26 \\
9 \\
9\end{array}$ \\
\hline $\begin{array}{l}\text { Practice type } \\
\text { Solo } \\
\text { Single Specialty Group } \\
\text { Multi-Specialty Group } \\
\text { Other }\end{array}$ & $\begin{array}{l}46.9 \\
42.9 \\
16.7 \\
22.2\end{array}$ & $\begin{array}{l}53.1 \\
57.1 \\
83.3 \\
77.8\end{array}$ & $\begin{array}{r}32 \\
28 \\
6 \\
9\end{array}$ \\
\hline $\begin{array}{l}\text { Hours of direct patient car } \\
5 \text { to } 25 \\
26 \text { to } 35 \\
>35\end{array}$ & $\begin{array}{c}22.2 \\
0 \\
46.6\end{array}$ & $\begin{array}{r}77.8 \\
100.0 \\
53.4\end{array}$ & $\begin{array}{r}9 \\
7 \\
58\end{array}$ \\
\hline $\begin{array}{l}\text { Change in financial net, p } \\
\text { Increased } \\
\text { Unchanged } \\
\text { Decreased }\end{array}$ & $\begin{array}{l}52.4 \\
39.3 \\
27.3\end{array}$ & $\begin{array}{l}47.6 \\
60.7 \\
72.7\end{array}$ & $\begin{array}{l}21 \\
28 \\
22\end{array}$ \\
\hline
\end{tabular}


Table 2. Physicians' Reporting of Proportion of Ambulatory Visits by Payment Types

\begin{tabular}{|c|c|c|}
\hline \multirow[b]{2}{*}{ Payment Type and Proportion of Visits } & \multicolumn{2}{|c|}{ Physicians } \\
\hline & Number & $\%$ \\
\hline $\begin{array}{l}\text { Public (Medicare and Medicaid)* }(\mathrm{N}=66) \\
\quad \leq 30 \% \\
>30 \%\end{array}$ & $\begin{array}{l}35 \\
31\end{array}$ & $\begin{array}{l}53.0 \\
47.0\end{array}$ \\
\hline $\begin{array}{l}\text { Sliding scale }(\mathrm{N}=64) \\
\text { None } \\
<10 \% \\
\geq 10 \%\end{array}$ & $\begin{array}{l}38 \\
15 \\
11\end{array}$ & $\begin{array}{l}59.4 \\
23.4 \\
17.2\end{array}$ \\
\hline $\begin{array}{l}\text { Free care }(\mathrm{N}=63) \\
\quad \text { None } \\
<10 \% \\
\geq 10 \%\end{array}$ & $\begin{array}{r}16 \\
44 \\
3\end{array}$ & $\begin{array}{r}25.4 \\
69.8 \\
4.8\end{array}$ \\
\hline $\begin{array}{l}\text { Debt forgiveness }(\mathrm{N}=64) \\
\quad \text { None } \\
<10 \% \\
\geq 10 \%\end{array}$ & $\begin{array}{r}15 \\
45 \\
4\end{array}$ & $\begin{array}{r}23.4 \\
70.3 \\
6.3\end{array}$ \\
\hline $\begin{array}{l}\text { Bad debt }(\mathrm{N}=63) \\
\quad \text { None } \\
\quad<10 \% \\
\geq 10 \%\end{array}$ & $\begin{array}{r}7 \\
37 \\
19\end{array}$ & $\begin{array}{l}11.1 \\
58.7 \\
30.2\end{array}$ \\
\hline
\end{tabular}

* No physicians reported $0 \%$ to $5 \%$ billed to Medicare and Medicaid.

practice $(6.8 \%)$, and limiting care to emergencies only $(6.8 \%)$ (not tabled).

Charity Care, Sliding Scales, Debt Forgiveness, and Other Parts of the Safety Net

Only $17.2 \%$ of respondents claimed more than $10 \%$ of their visits were billed on a sliding scale, and $59.4 \%$ claimed no visits with a sliding scale
(Table 2). The decision to offer a sliding fee scale did not differ by years in practice, income, or gender of responding physician.

More than 3 in 4 FP/GPs said they offered free care, debt forgiveness, and had billings for which they did not collect (bad debt), with 4.8\%, 6.3\%, and $30.2 \%$ reporting greater than or equal to $10 \%$ of their visits attributed to free care, debt forgiveness, or bad debt, respectively (Table 2). In addition, consistent with the prevalence of insurance discounts, only $9.5 \%$ responded that they gave no insurance discounts (not tabled).

\section{The Distribution of Charity Care}

There was a significant difference among physicians when comparing those who had greater than or equal to $10 \%$ of their visits as nonpaying (free care, debt forgiveness, or bad debt) with those who had fewer than $10 \%$ as nonpaying, regarding their perception of whether charity care was evenly or unevenly distributed in the community $(P<.05)$ (Table 3$)$. Of those having fewer than $10 \%$ of their visits as nonpaying, $87.1 \%$ perceived the distribution to be uneven compared with $67.7 \%$ of those with $10 \%$ or more.

Income was not significantly associated with the perception of one's relative contribution (Figure 1).

The perception of overall fairness did vary significantly, however, by the physician's view of the burden s/he had. Of those who perceived the situation as uneven, $75.4 \%$ indicated they did more than their share $(P<.000)$ (not tabled), compared

Table 3. Distribution of Physicians by Proportion of Visits That Were Nonpaying* and by Physician Characteristics

\begin{tabular}{lcc}
\hline Physician Characteristics & $\begin{array}{c}10 \% \text { or Greater of Visits } \\
\text { by Nonpaying Patients }\end{array}$ & $\begin{array}{c}\text { Less than } 10 \% \text { of Visits } \\
\text { by Nonpaying Patients }\end{array}$ \\
\hline Number & 34 & 33 \\
Gender & $\mathrm{N}=34$ & $\mathrm{~N}=32$ \\
Male (\%) & 82.4 & 84.4 \\
Female (\%) & 17.6 & 15.6 \\
Location of practice & $\mathrm{N}=33$ & $\mathrm{~N}=33$ \\
Urban & 18.2 & 27.3 \\
Rural & 81.8 & 72.0 \\
Income per year & $\mathrm{N}=33$ & $\mathrm{~N}=31$ \\
$\quad \$ 130,000$ & 69.7 & 48.4 \\
$\quad \$ 130,000$ & 30.3 & 51.6 \\
Perception of distribution of charity care in the community $\dagger$ & $\mathrm{N}=33$ & $\mathrm{~N}=31$ \\
Even & 33.3 & 12.9 \\
Uneven & 67.7 & 87.1 \\
Perception of personal share of charity care in the community & $\mathrm{N}=33$ & $\mathrm{~N}=32$ \\
Greater than others & 60.6 & 59.4 \\
Less than or equal to others & 39.4 & 40.6 \\
\hline
\end{tabular}

* Nonpaying includes free care, debt forgiveness, and bad debt.

$+P<.05$. 


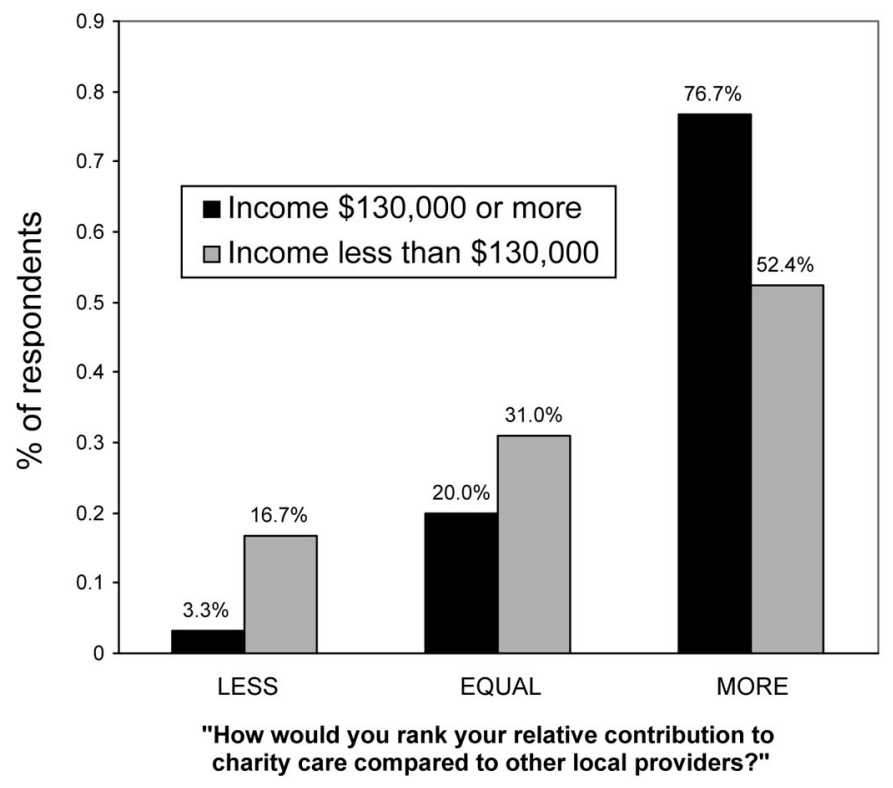

Figure 1. Perceived Relative Contribution of Charity Care by Income of Physician.

with $17.6 \%$ of those who thought the burden was distributed evenly. None of those who reported an increase in income during the previous 2 years said they decreased their charity care contribution, whereas $39.1 \%$ of those whose income had decreased also decreased their provision of charity care $(P<.05)$ (Figure 2).
Costs of the Safety Net

Respondents were asked to report the extent of their charity care in both percentage of visits as well as dollar amounts, estimating numbers for publicly financed patients, bad debt, free care, sliding scale, and installment plans, as well as the portion of visits that were on private insurance discount. The sur-

$$
p<0.05
$$

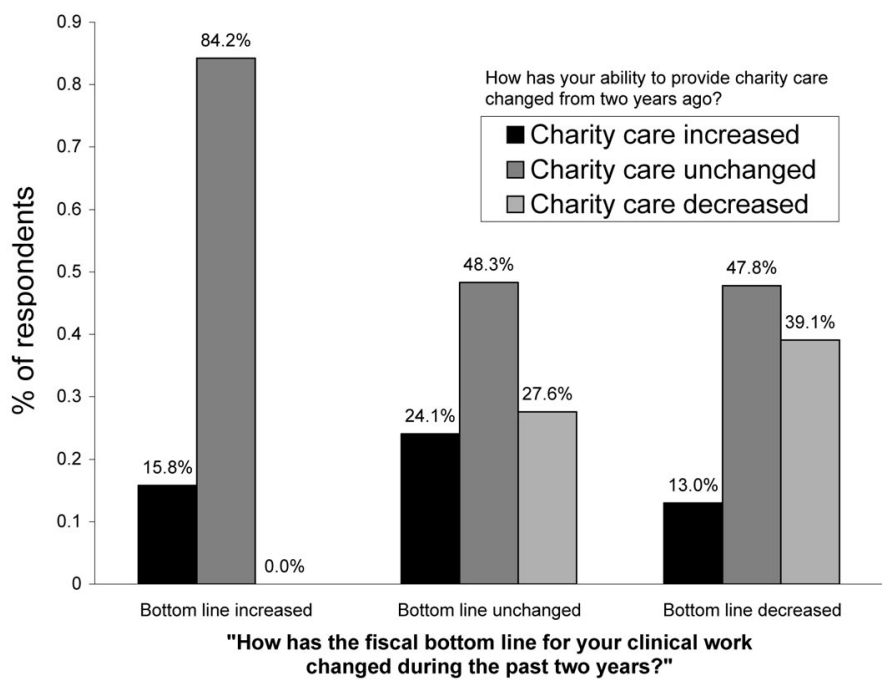

Figure 2. The Relationship between Recent Changes in the Respondent Physicians' Clinical Income and Changes in the Amount of Charity Care Provided. 
vey question required that respondents account for all the care they provided for which they did not receive full reimbursement. Although $56.6 \%$ of FP/ GPs had unbilled charges estimated between $\$ 1,001$ and $\$ 10,000$, another $30.4 \%$ estimated unbilled charges as greater than $\$ 10,000$ (Table 4). The range was from $\$ 500$ to $\$ 50,000$. Only 4 respondents $(9.8 \%)$ said they forgave zero debt. Twelve physicians $(29.3 \%)$ forgave more than $\$ 10,000$ in debt during the prior year (Table 4).

Most physicians reported bad debt. Of those who estimated a dollar amount for bad debt, $28.3 \%$ said they had lost more than $\$ 50,000$ (Table 4). The median for free care (not billed), forgiven debt, and bad debt was $\$ 39,000$, with a mean of $\$ 54,283$ per physician. Only $26.7 \%$ of physicians reported that their collections came to $90 \%$ or more of billed charges. A small portion (11.7\%) said they collected under $60 \%$ of billed charges.

\section{Who Decides about Charity Care?}

Most respondents (75.6\%) made their own charity care policies. Almost one fourth $(23.1 \%)$ said their ability to provide charity care had decreased compared with 2 years ago, whereas $16.7 \%$ said they were able to provide more. In comments made on the survey, several of those who were providing less

Table 4. Costs to Physicians Participating in the Safety Net

\begin{tabular}{lcr}
\hline & \multicolumn{2}{c}{ Physicians } \\
\cline { 2 - 3 } & Number & $\%$ \\
\hline & & \\
Gross billings not billed ${ }^{*}(\mathrm{~N}=46)$ & 6 & 13.0 \\
$\leq \$ 1,000$ & 26 & 56.6 \\
$\$ 1,001$ to $\$ 10,000$ & 14 & 30.4 \\
$\$ 10,001$ to $\$ 50,000$ & & \\
Gross billings, billed not received, and & & \\
$\quad$ forgiven debt $(\mathrm{N}=41)$ & 10 & 24.4 \\
$\leq \$ 1,000$ & 19 & 46.3 \\
$\$ 1,001$ to $\$ 10,000$ & 12 & 29.3 \\
$\$ 10,001$ to $\$ 50,000$ & & \\
Gross billings, billed and not collected $\dagger$ & & \\
$\quad(\mathrm{N}=45)$ & 3 & 6.5 \\
$\leq \$ 1,000$ & 10 & 21.8 \\
$\$ 1,001$ to $\$ 10,000$ & 20 & 43.4 \\
$\$ 10,001$ to $\$ 50,000$ & 12 & 28.3 \\
$>\$ 50,000$ & & \\
Percentage of billed that was collected & & \\
$(\mathrm{N}=60)$ & 7 & 11.7 \\
$40 \%$ to $60 \%$ & 37 & 51.6 \\
$61 \%$ to $89 \%$ & 16 & 26.7 \\
$\geq 90 \%$ & & \\
\hline
\end{tabular}

* Did not plan on being paid.

† Bad debt. said their overhead had increased whereas their incomes had not. Several indicated a belief that Medicare prohibited variation in fee structure or made fiscal accommodations for non-Medicare insured patients. Income, income changes, years in practice, and gender did not significantly predict a decrease in charity care from prior years.

\section{Conclusions}

Wyoming FP/GPs, 75\% of whom practiced in rural areas, were an important part of the informal health care safety net for vulnerable people in their communities. Although most of the physicians were not earning a mean income of $\$ 130,000$, most of the respondents perceived themselves to be doing their share in caring for those who could not pay for services.

Most respondents, especially if they reported doing more than their share, thought the safety net burden was not evenly shared within their communities. It is possible that our respondents are a biased group from those more likely to provide more of this care. Alternatively, this finding may simply be representative of the tendency of people to see themselves as above average.

Perhaps most important, those whose bottom line declined or remained static were more likely to have decreased their level of charity care contribution. The finding that charity care declines with declining income is salient. With the average respondent attributing $43 \%$ of visits to public insurance, debt forgiveness, free care, or bad debt, these physicians are particularly vulnerable to any decrease in income. With flat Medicare funding and cuts in Medicaid eligibility and scope of coverage, more Americans will become underinsured or uninsured. The need for the safety net will be increasing just as the ability and willingness of these providers to participate is eroded further.

The high-giving group was different from those giving less in other ways as well. Those earning above $\$ 130,000$ were more likely to perceive themselves as doing more, and women were more likely than men to think the burden was shared evenly.

The main limitation of this study was the small number of responding physicians. Second, we know little about the nonrespondents except that they do not differ by gender or community size. Our respondents also do not differ significantly in age distribution or gender from all primary care 
physicians (family medicine, internal medicine, pediatrics) in Wyoming. ${ }^{13}$ We could not ascertain whether nonrespondents differ from respondents in the care of the underinsured or uninsured. Although a higher response rate would improve the power to discern statistically significant differences between different groups of interest, the respondents do represent half of all the FP/GPs in Wyoming.

Third, the physicians in this study are from only one state and one discipline; this raises questions about the generalizability of the findings. FPs and GPs do, however, account for $62.7 \%$ of the primary care doctors in Wyoming. ${ }^{13}$ Fourth, we cannot differentiate between proportions of physician visits to Medicaid as opposed to Medicare patients. The 2 programs have different discounts for some services. We did not explore the differences among Medicare, Medicaid, and private insurance discounts. Last, more work is needed to replicate and externally validate these findings and to examine both rural and urban components of the provider safety net.

Based on our participation in the previously cited safety net case study, ${ }^{11}$ we conjecture that physicians do not like to think about how much care they are giving away and actually may be underestimating the amounts. Indeed, during some of those case study visits, physicians said we were welcome to look at their records but to please not inform them of our specific findings. They did not want to know what they were giving away. There are likely complicated psychological and economic reasons for this that have not been explored. Several respondents in this study indicated that they believed Medicare puts constraints on what can be given away, so some of the reticence to discuss the issue may be because of fear that disclosure of charging some patients less could be viewed as unethical or fraudulent. Alternatively, some physicians may choose not to know because of a concern that knowing might influence them to not provide needed care to the vulnerable in their communities. The overall reluctance to discuss may also help explain our relatively low response rate for this study.

Nonetheless, physicians in this one largely rural state, Wyoming, were providing safety net care, serving the uninsured and underinsured, including the publicly insured and other patients with notable discounts. Despite the effects on their economic bottom line, they supported the health care infrastructure in their communities and helped those who had difficulty paying for necessary care.

Whereas the nation's underinsured and uninsured are increasing, the federal government has taken steps to increase certain components of the formal structure or formal safety net. For instance, a significant increase in funding to increase both capacity and geographic coverage of federally funded health centers is in process. Nevertheless, many Americans still depend on a safety net for their health care characterized by an informal system of individual physicians, hospitals, and other care providers in communities, all of whom absorb loss or displace it to other patients. In Wyoming, a substantial portion of safety net care is provided informally by the family and general physicians.

Our study gives shape and definition to one part of the safety net and raises the question whether relying on private physician good will is the most rational approach to providing a secure health care delivery system for rural or poor Americans, especially when we see that physicians with decreasing incomes report delivering less charity care. Although there are many who argue that physicians are no longer charitable and altruistic, these results show that Wyoming FP/GPs provide substantial amounts of charity care at no small expense to themselves.

It is important to know about this part of the safety net to ensure the policies do not hinder the charity care efforts of FPs and GPs. A thoughtful public policy-formed collectively by physicians, patients, and others-is required to strengthen the safety net at levels other than individual examination rooms.

We appreciate the assistance of the Wyoming Medical Society in conducting the survey of family physicians required for this study. The opinions expressed in this article are solely the responsibility of the authors. Contributorship: Sharon Dobie designed the study and the instrument, conducted the study, and was a primary person involved in interpretation of the data, writing, and revising the manuscript. Amy Hagopian was a primary person involved in analyzing the data, interpretation of the data, and writing the manuscript. Beth Kirlin was involved in the analysis of the data. Gary Hart designed the study and the instrument, conducted the study, and was closely involved in interpretation of the data and writing the manuscript.

\section{References}

1. Bergman M. Numbers of Americans with and without health insurance rise, Census Bureau reports. 
U.S. Census Bureau Web site. Available from: http://www.census.gov/Press-Release/www/releases/ archives/health_care_insurance/001372.html. Accessed 2004 February 10.

2. Minnesota Hospitals and Health Care Partnership. A benefit to the community: accounting for uncompensated care, a report of the Uncompensated Care Work Group to the MHHP Board of Directors. Available from: http://www.health.state.mn.us/divs/ hpsc/hep/uncompcare/defn_analysis.htm. Accessed 2005 June 27.

3. Weil A. There's something about Medicaid. Health Aff (Millwood) 2003;22:13-30.

4. Ormand BA, Wall Wallin S, Goldenson SM. Supporting the rural health care safety net. Urban Institute Web site. Available from: http://www. urban.org/url.cfm?ID=309437. Accessed 2005 June 27.

5. Lewin ME, Altman S, eds. America's health care safety net: Intact but endangered. Washington, DC: Institute of Medicine Committee on the Changing Market, Managed Care and the Future Viability of Safety Net Providers, National Academies Press; 2000.

6. Kane CK. Physician provision of charity care, $1988-$ 1999. Chicago (IL): American Medical Association; 2002.
7. Felland LE, Lesser CS, Staiti AB, Katz A, Lichiello P. The resilience of the health care safety net, 19962001. Health Serv Res 2003;38:489-502.

8. The budget politics of being poor. New York Times. 2003 Dec 31;Sect. A:18.

9. Waitzkin H, Williams RL, Bock JA, McCloskey J, Willging C, Wagner W. Safety-net institutions buffer the impact of Medicaid managed care: a multimethod assessment in a rural state. Am J Public Health 2002;92:598-610.

10. Sutton J, Blanchfield B, Singer A, Milet M. Is the rural safety net at risk? Analysis of charity care provided by rural hospitals in 5 states. Project HOPE policy analysis brief. Millwood, VA; Project HOPE; 2001.

11. Taylor P, Blewett L, Brasure M, et al. Small town health care safety nets: report on a pilot study. J Rural Health 2003;19:125-34.

12. Morrill R, Cromartie J, Hart LG. Metropolitan, urban, and rural commuting areas: toward a better depiction of the US settlement system. Urban Geogr 1999;20:727-48.

13. Pasko T, Seidman B, Birkhead S. Physician characteristics and distribution in the United States, 20012002. Chicago (IL): American Medical Association; 2001. 